\title{
Associations of the PON1 rs662 polymorphism with circulating oxidized low-density lipoprotein and lipid levels: a systematic review and meta-analysis
}

\author{
Zhi Luo ${ }^{*}$, Lijun Pu ${ }^{\dagger}$, Irfan Muhammad, Yun Chen and Xiaoqian Sun
}

\begin{abstract}
Background: Several meta-analyses have demonstrated that the rs662 polymorphism in Paraoxonase 1 gene (PON1) gene is associated with coronary heart disease (CHD). However, it is still uncertain whether this polymorphism is associated with the plasma levels of oxidized low-density lipoprotein (Ox-LDL) and lipids. This meta-analysis is aimed to clarify the relationships between the rs662 polymorphism and plasma levels of Ox-LDL and lipids.

Methods: By searching in PubMed, Google Scholar, Web of Science, Cochrane Library, Wanfang, VIP and CNKI databases, 5 studies (1369 subjects) and 85 studies (46,740 subjects) were respectively identified for Ox-LDL association analysis and lipid association analysis. Standardized mean difference (SMD) was used to estimate the effects of the rs662 polymorphism on plasma Ox-LDL and lipid levels.

Results: The carriers of the variant $\mathrm{R}$ allele had higher levels of Ox-LDL (SMD $=0.23,95 \% \mathrm{Cl}=0.10-0.36, P<0.01$ ), triglyceride $(\mathrm{TG})(\mathrm{SMD}=0.06,95 \% \mathrm{Cl}=0.01-0.11, P=0.02)$, total cholesterol $(\mathrm{TC})(\mathrm{SMD}=0.04,95 \% \mathrm{Cl}=0.00-0.07, P=0$. $05)$ and low-density lipoprotein cholesterol ( $L D L-C)(S M D=0.04,95 \% \mathrm{Cl}=0.00-0.08, P=0.04)$ than the non-carriers.

Conclusions: This meta-analysis suggests that the association between the PON1 rs662 polymorphism and CHD may partly be mediated by abnormal Ox-LDL and lipid levels caused by the R allele.
\end{abstract}

Keywords: Paraoxonase 1, Oxidized low-density lipoprotein, Lipid, Polymorphism, Coronary heart disease

\section{Introduction}

Coronary heart disease (CHD) is currently the leading cause of death in developed and some developing countries like China [1]. CHD is a multifactorial disease with a number of risk factors being identified in the past few decades. Among these risk factors, the increase in circulating oxidized low-density lipoprotein (Ox-LDL) and dyslipidemia were widely reported with regard to their important roles in the occurrence and development of $\mathrm{CHD}[2,3]$. Ox-LDL, formed by oxidative modification of low density lipoprotein, is thought to play a key role in atherogenesis and induce a wide range of biological effects on smooth muscle cells. Dyslipidemia is a state of abnormal amounts

\footnotetext{
* Correspondence: 2454912230@qq.com

${ }^{\dagger}$ Zhi Luo and Lijun Pu contributed equally to this work.

Department of Cardiology, Affiliated Hospital of North Sichuan Medical College, Nanchong 637000, People's Republic of China
}

of lipids (e.g., triglycerides, cholesterol and/or phospholipids) in the blood, and is characterized by increased levels of triglycerides (TG), total cholesterol (TC) and low-density lipoprotein cholesterol (LDL-C), and/or decreased level of high-density lipoprotein cholesterol (HDL-C) in circulation. Intensive efforts have been made in the scientific community to investigate the associations of the genetic polymorphisms in specific genes with the risk factors for CHD, but the results were inconsistent and inconclusive. It is difficult to successfully identify the genetic polymorphisms being associated with the risk factors for CHD due to various reasons such as small sample sizes and ethnic differences.

In humans, PON has three isoforms: paraoxonase 1 (PON1), paraoxonase 2 (PON2) and paraoxonase 3 (PON3). Among them, PON1 is a calcium-dependent multifunctional enzyme that connects metabolisms of homocysteine (Hcy) and lipoproteins. First of all, PON1 plays a key role in

(C) The Author(s). 2018 Open Access This article is distributed under the terms of the Creative Commons Attribution 4.0 International License (http://creativecommons.org/licenses/by/4.0/), which permits unrestricted use, distribution, and 
Hcy metabolism by irreversibly catalyzing the conversion of homocysteine thiolactone (Hcy T) to Hcy. By detoxifying Hcy T, the PON1 would protect proteins against homocysteinylation, a potential risk factor for CHD [4]. Secondly, PON1 is a HDL-associated enzyme that inhibits the oxidation of LDL [5] and HDL [6] as well as promote cholesterol efflux from macrophage foam cells [7]. PON1 has been reported to be associated with abnormal lipid levels and CHD risk $[8,9]$. Shih et al. [10] reported that PON1 (-/-) mice had significantly higher levels of plasma Ox-LDL and Ox-HDL compared with PON1 $(+/+)$ mice. When fed on a high-fat diet, PON1 (-/-) mice were more susceptible to atherosclerosis than PON1 (+/+) mice.

The PON1 gene is located on the long arm of human chromosome 7 (7q21.3-22.1), and it contains 9 exons and 8 introns. There are several polymorphisms in the PON1 gene. The rs662 polymorphism (also known as Q192R) is located in exon 6 of the PON1 gene and formed by a transition from adenine (A) to guanine (G). Accordingly, the 192th genetic code is changed from CAA to CGA, resulting in the replacement of glutamine (Gln) by arginine (Arg) in the PON1 polypeptide. A large number of researches have investigated the associations of the rs662 polymorphism with plasma Ox-LDL and lipid levels. In some of these studies, the $\mathrm{R}$ allele of the rs662 polymorphism was reported to be associated with increased levels of Ox-LDL [11, 12], TG [9, 13, 14], TC [8, 9, 15] and LDL-C $[8,9,15-17]$, and reduced levels of HDL-C [18-20]. However, the results obtained from other studies did not support these findings [21-23]. Hence, a meta-analysis is required to clarify the relationships of the rs662 polymorphism with Ox-LDL and lipids.

In this study, a systematic review and meta-analysis was performed based on previous publications to investigate the associations of the rs662 polymorphism with Ox-LDL and lipid levels. Our analysis results can provide an opportunity to unveil the interrelationships among the rs662 polymorphism, Ox-LDL, dyslipidemia and susceptibility to CHD.

\section{Methods}

\section{Literature search}

The articles published until September 2018 on the associations of the rs662 polymorphism with circulating Ox-LDL and lipid levels were identified. The languages of the articles were limited to English and Chinese. A comprehensive search was conducted and nine electronic databases were searched to identify all relevant articles. The databases were as follows: PubMed, Embase, Baidu Scholar, Google Scholar, Web of Science, Cochrane Library, Wanfang, CBM and CNKI. The following keywords were used: ("Paraoxonase 1" or "PON1"), ("Q192R" or "rs662" or "Gln192Arg"), ("polymorphism" or "mutation" or "variant"), ("Ox-LDL” or "oxidized low-density lipoprotein") and ("plasma lipid" or "blood lipid" or "serum lipid").

\section{Inclusion and exclusion criteria}

The inclusion criteria for the meta-analysis are as follows: 1) studies which presented the genotype and allele frequencies of the rs662 polymorphism; 2) studies in which mean Ox-LDL and mean lipids with standard deviation (SD) or standard error (SE) according to the rs662 genotypes were available; 3) studies which reported at least one of the five variables, i.e., Ox-LDL, TG, TC, LDL-C and HDL-C. All references cited by the included articles were reviewed to check the published work which was not indexed by PubMed, Embase, Baidu Scholar, Google Scholar, Web of Science, Cochrane Library, Wanfang, CBM and CNKI. Reports with incomplete data, studies based on pedigree data, case reports, review articles, abstracts and animal studies were excluded from the meta-analysis. Pre-intervention data were used for interventional studies.

\section{Data extraction}

Data were extracted from each study by using a structured data collection form and by two investigators independently according to the pre-specified selection criteria. Decisions were compared and disagreements about study selection were resolved by consensus or involving a third investigator. For the overlapping articles, only the publications that presented the most detailed information were included. In this meta-analysis, the data extracted from each of the included studies are as follows: first author, year of publication, age, ethnicity, gender, health status, type of study, lipid assay method, sample size, and mean with SD or SE according to the rs662 genotypes. If data in a study were unconvincing, we attempted to contact the corresponding or first author by e-mail or telephone.

\section{Data analysis}

Statistical analysis was performed using STATA version 12.0 (Stata Corporation LP, College Station, TX, USA). All the tests were two-sided and a $P$-value of less than 0.05 for any test or model was considered to be statistically significant. The pooled standardized mean difference (SMD) with 95\% confidence interval (CI) was used to assess the strength of the associations between the rs662 polymorphism and plasma levels of Ox-LDL and lipids. Random-effect model (DerSimonian-Laird method) was used to evaluate the results if heterogeneity among the included studies was significant $\left(I^{2}>50 \%\right)$. Otherwise, Fixed-effect model (Mantel-Haenszel method) was used [24]. Heterogeneity was investigated by Cochran's $\chi^{2}$-based Q-statistic, and Galbraith plots were used to detect the potential sources of heterogeneity. SMD values were 
recalculated after excluding the studies with heterogeneity. Subgroup analyses were performed according to gender, ethnicity and health status. Ethnic subgroup was defined as Caucasian, Asian, African, and the subjects of other ethnic origin. Health status was defined as CHD, T2DM and Hyperlipidemia. HWE was assessed by Fisher's exact test. Publication bias was tested by Begg's funnel plot and Egger's test [25].

\section{Result}

\section{Characteristics of the included studies}

Initial search of the databases yielded 2481 articles. Two thousand one hundred and eighty-five studies were excluded according to titles and abstracts. Then full-text articles were retrieved and assessed on the basis of the inclusion criteria. Forty studies were ineligible for the following reasons: 28 studies presented data for other polymorphisms, 4 studies had subjects overlapping with other publications, 5 studies were based on pedigree analysis, and 3 studies were treated with lipid-lowering drugs. In the end, 85 studies were selected for this meta-analysis (Fig. 1). Of them, 5 studies (1369 subjects) were included in the Ox-LDL association analysis and 85 studies (46,740 subjects) were included in the lipid association analysis. The references for the studies included in the present meta-analysis were listed in Additional file 1.

The characteristics of the studies included in the Ox-LDL and lipids association analysis were summarized in Additional file 2: Table S1. The plasma Ox-LDL levels by the genotypes of the rs662 polymorphism were presented in Additional file 2: Table S2. One study and 4 studies were involved in Caucasians and Asians, respectively. The plasma lipid levels by the genotypes of the rs662 polymorphism were presented in Additional file 2: Table S3. Forty-three studies, 25 studies, 5 studies and 12 studies were involved in Caucasians, Asians, Africans and the subjects of other ethnic origins, respectively.

\section{Association of the rs662 polymorphism with ox-LDL}

The carriers of the variant $\mathrm{R}$ allele had higher levels of Ox-LDL $\quad(\mathrm{SMD}=0.23, \quad 95 \% \quad \mathrm{CI}=0.10-0.36, \quad P<0.01)$ (Table 1, Fig. 2) than the non-carriers. When the analysis was limited to the studies in HWE, the association between the rs662 polymorphism and Ox-LDL was also significant $(\mathrm{SMD}=0.32,95 \% \mathrm{CI}=0.12-0.53, P<0.01)$ (Table 1$)$.

The subgroup analyses stratified by the characteristics of the subjects were performed, and the results showed that the rs662 polymorphism was significantly associated with Ox-LDL levels in Asians and CHD patients (Table 1).

\section{Associations of the rs662 polymorphism with plasma lipid levels}

The outcomes of the analysis on all comparisons showed that the $\mathrm{R}$ allele carriers had higher levels of TG $(\mathrm{SMD}=0.06,95 \% \mathrm{CI}=0.01-0.11, P=0.02), \quad \mathrm{TC}$ $(\mathrm{SMD}=0.04,95 \% \mathrm{CI}=0.00-0.07, P=0.05)$ and LDL-C $(\mathrm{SMD}=0.04,95 \% \mathrm{CI}=0.00-0.08, P=0.04)$ than the non-carriers (Table 2, Figs. 3, 4 and 5), and that there was no association detected between the rs662 polymorphism and plasma levels of HDL-C (SMD $=-0.01$, 95\% CI $=-0.05-0.04, P=0.68$ ) (Table 2, Fig. 6). When the analysis was limited to the studies in HWE, the $R$

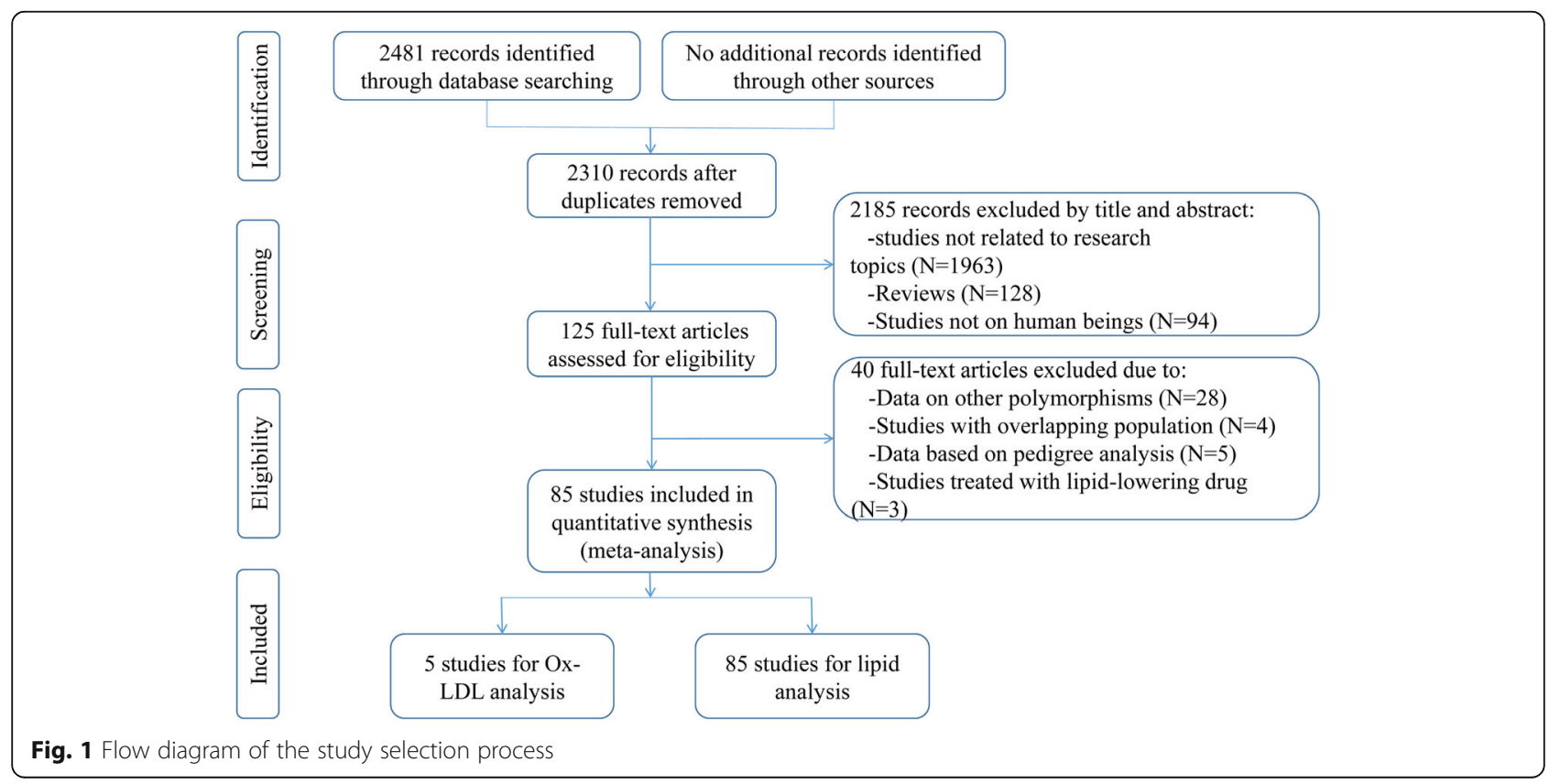


Table 1 Meta-analysis between the PON1 rs662 polymorphism and Ox-LDL levels

\begin{tabular}{|c|c|c|c|c|}
\hline Groups or subgroups & Comparisons (Subjects) & SMD (95\% Cl) & $P_{\text {Heterogeneity }}$ & $P_{\text {SMD }}$ \\
\hline \multicolumn{5}{|l|}{ Ox-LDL } \\
\hline All & $13(1369)$ & $0.23(0.10-0.36)$ & $<0.01$ & $<0.01$ \\
\hline Studies in HWE & $3(426)$ & $0.32(0.12-0.53)$ & $<0.01$ & $<0.01$ \\
\hline Caucasian & $2(345)$ & $-0.16(-0.37-0.06)$ & 0.34 & 0.15 \\
\hline Asian & $11(1024)$ & $0.44(0.28-0.60)$ & $<0.01$ & $<0.01$ \\
\hline $\mathrm{CHD}$ & $3(274)$ & $0.39(0.12-0.66)$ & $<0.01$ & $<0.01$ \\
\hline Healthy or control & $4(518)$ & $0.03(-0.16-0.22)$ & 0.63 & 0.74 \\
\hline
\end{tabular}

PON1 Paraoxonase 1 gene, SMD standardized mean difference, 95\% Cl 95\% confidence interval, HWE Hardy-Weinberg equilibrium, Ox-LDL oxidized low density lipoprotein, $C H D$ coronary heart disease

allele carriers had higher level of TG (SMD $=0.06,95 \%$ $\mathrm{CI}=0.00-0.12, P=0.04)$ and LDL-C $(\mathrm{SMD}=0.04,95 \% \mathrm{CI}$ $=0.00-0.09, P=0.04)$ than the non-carriers (Table 2). No associations were found between the rs662 polymorphism and plasma levels of TC $(\mathrm{SMD}=0.03,95 \% \mathrm{CI}=-$ $0.01-0.07, P=0.13)$ and HDL-C $(\mathrm{SMD}=-0.01,95 \% \mathrm{CI}=$ $-0.05-0.04, P=0.78$ ) (Table 2).

Then the subgroup analysis stratified by the characteristics of the subjects was performed. The significant association of the rs662 polymorphism with higher levels of LDL-C (SMD $=0.26,95 \% \mathrm{CI}=0.01-0.51, P=0.04$ ) was detected in the females, but not in the males. The significant associations of the rs662 polymorphism with higher levels of TG $(\mathrm{SMD}=0.12,95 \% \mathrm{CI}=0.00-0.23, P$ $=0.04), \mathrm{TC}(\mathrm{SMD}=0.14,95 \% \mathrm{CI}=0.05-0.24, P<0.01)$ and LDL-C $(\mathrm{SMD}=0.13,95 \% \mathrm{CI}=0.01-0.26, P=0.04)$ were detected in Asians, but not in the other ethnicities. When health status was taken into account, the significant association of the rs662 polymorphism with higher levels of TG was detected in CHD patients and T2DM patients, but not in hyperlipidemia patients and healthy subjects; the significant association of the rs662 polymorphism with higher levels of TC (SMD $=0.07,95 \%$ $\mathrm{CI}=0.01-0.14, P=0.04)$ was only detected in healthy subjects, but not in CHD patients, T2DM patients and hyperlipidemia patients; furthermore, association of the rs662 polymorphism with higher levels of LDL-C was detected in T2DM patients and healthy subjects, but not in CHD patients and hyperlipidemia patients; continuously, association of the rs662 polymorphism with lower levels of HDL-C $(\mathrm{SMD}=-0.06,95 \% \mathrm{CI}=-0.12--0.01, P$ $=0.02$ ) was only detected in CHD patients, but not in

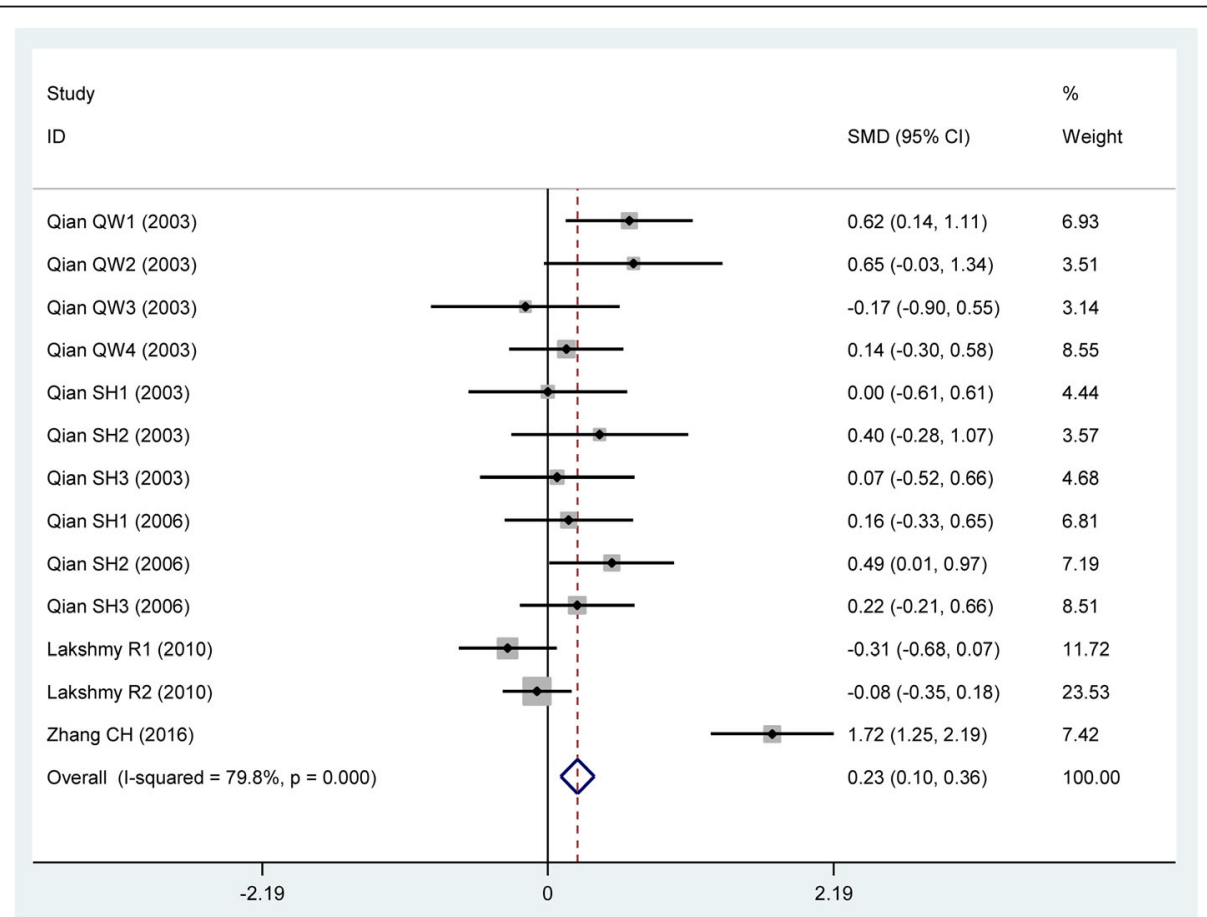

Fig. 2 Forest plot of the meta-analysis between the PON1 rs662 polymorphism and circulating oxidized low-density lipoprotein (Ox-LDL) levels 
Table 2 Meta-analysis between the PON1 rs662 polymorphism and plasma lipid levels

\begin{tabular}{|c|c|c|c|c|}
\hline Groups or subgroups & Comparisons (Subjects) & $\operatorname{SMD}(95 \% \mathrm{Cl})$ & $P_{\text {Heterogeneity }}$ & $P_{S M D}$ \\
\hline \multicolumn{5}{|l|}{$\overline{T G}$} \\
\hline All & $91(24,704)$ & $0.06(0.01-0.11)$ & $<0.01$ & 0.02 \\
\hline Studies in HWE & $64(20,340)$ & $0.06(0.00-0.12)$ & $<0.01$ & 0.04 \\
\hline Male & $5(3322)$ & $-0.01(-0.26-0.24)$ & $<0.01$ & 0.93 \\
\hline Female & $6(1210)$ & $0.10(-0.04-0.25)$ & 0.73 & 0.15 \\
\hline Caucasian & $32(11,555)$ & $0.06(-0.01-0.13)$ & $<0.01$ & 0.08 \\
\hline Asian & $35(7659)$ & $0.12(0.00-0.23)$ & $<0.01$ & 0.04 \\
\hline African & $6(1880)$ & $0.03(-0.09-0.15)$ & 0.94 & 0.58 \\
\hline Other ethnicity & $18(3610)$ & $-0.00(-0.10-0.10)$ & 0.02 & 0.98 \\
\hline $\mathrm{CHD}$ & $16(3912)$ & $0.10(0.04-0.17)$ & $<0.01$ & $<0.01$ \\
\hline $\mathrm{T} 2 \mathrm{DM}$ & $10(1715)$ & $0.18(0.07-0.28)$ & 0.03 & $<0.01$ \\
\hline Hyperlipidemia & $3(296)$ & $-0.13(-0.43-0.17)$ & 0.66 & 0.39 \\
\hline Healthy or control & $36(8693)$ & $0.03(-0.02-0.08)$ & 0.30 & 0.22 \\
\hline \multicolumn{5}{|l|}{ TC } \\
\hline All & $103(33,696)$ & $0.04(0.00-0.07)$ & $<0.01$ & 0.05 \\
\hline Studies in HWE & $75(27,792)$ & $0.03(-0.01-0.07)$ & $<0.01$ & 0.13 \\
\hline Male & $5(4354)$ & $-0.03(-0.09-0.03)$ & 0.58 & 0.26 \\
\hline Female & $4(914)$ & $0.19(-0.03-0.40)$ & 0.24 & 0.09 \\
\hline Caucasian & $46(19,714)$ & $0.01(-0.03-0.05)$ & 0.01 & 0.65 \\
\hline Asian & 36 (7869) & $0.14(0.05-0.24)$ & $<0.01$ & $<0.01$ \\
\hline African & $3(1051)$ & $0.10(-0.15-0.35)$ & 0.22 & 0.42 \\
\hline Other ethnicity & $18(5062)$ & $-0.02(-0.10-0.07)$ & 0.07 & 0.68 \\
\hline $\mathrm{CHD}$ & $19(5995)$ & $0.01(-0.05-0.06)$ & 0.58 & 0.84 \\
\hline T2DM & $12(2213)$ & $0.12(-0.04-0.28)$ & $<0.01$ & 0.14 \\
\hline Hyperlipidemia & $3(296)$ & $-0.16(-0.46-0.14)$ & 0.75 & 0.29 \\
\hline Healthy or control & $40(11,168)$ & $0.07(0.01-0.14)$ & $<0.01$ & 0.04 \\
\hline \multicolumn{5}{|l|}{ LDL-C } \\
\hline All & $94(34,757)$ & $0.04(0.00-0.08)$ & $<0.01$ & 0.04 \\
\hline Studies in HWE & $73(31,416)$ & $0.04(0.00-0.09)$ & $<0.01$ & 0.04 \\
\hline Male & $4(1570)$ & $0.10(-0.22-0.02)$ & 0.72 & 0.08 \\
\hline Female & $4(914)$ & $0.26(0.01-0.51)$ & 0.12 & 0.04 \\
\hline Caucasian & $41(21,056)$ & $0.01(-0.03-0.05)$ & 0.01 & 0.49 \\
\hline Asian & 31 (7034) & $0.13(0.01-0.26)$ & $<0.01$ & 0.04 \\
\hline African & $4(1605)$ & $0.12(-0.17-0.40)$ & 0.02 & 0.43 \\
\hline Other ethnicity & $18(5062)$ & $0.02(-0.08-0.12)$ & 0.01 & 0.69 \\
\hline $\mathrm{CHD}$ & $16(5148)$ & $-0.01(-0.06-0.05)$ & 0.45 & 0.85 \\
\hline T2DM & $8(1446)$ & $0.36(0.03-0.69)$ & $<0.01$ & 0.03 \\
\hline Hyperlipidemia & $4(399)$ & $-0.09(-0.34-0.16)$ & 0.56 & 0.48 \\
\hline Healthy or control & $39(12,230)$ & $0.06(0.00-0.13)$ & $<0.01$ & 0.05 \\
\hline \multicolumn{5}{|l|}{$\mathrm{HDL}-\mathrm{C}$} \\
\hline All & $116(40,336)$ & $-0.01(-0.05-0.04)$ & $<0.01$ & 0.68 \\
\hline Studies in HWE & $87(34,743)$ & $-0.01(-0.05-0.04)$ & $<0.01$ & 0.78 \\
\hline Male & 7 (3729) & $0.03(-0.05-0.11)$ & 0.28 & 0.51 \\
\hline Female & $7(2724)$ & $-0.01(-0.09-0.07)$ & 0.63 & 0.78 \\
\hline
\end{tabular}


Table 2 Meta-analysis between the PON1 rs662 polymorphism and plasma lipid levels (Continued)

\begin{tabular}{lllll}
\hline Groups or subgroups & Comparisons (Subjects) & SMD (95\% Cl) & $P_{\text {Heterogeneity }}$ & $<0.01$ \\
\hline Caucasian & $54(26,409)$ & $-0.03(-0.08-0.02)$ & $<0.01$ & 0.22 \\
Asian & $35(7802)$ & $0.08(-0.06-0.22)$ & 0.09 & 0.25 \\
African & $8(2180)$ & $-0.01(-0.17-0.14)$ & $<0.01$ & 0.90 \\
Other ethnicity & $19(3945)$ & $-0.02(-0.12-0.09)$ & 0.01 & 0.76 \\
CHD & $18(5355)$ & $-0.06(-0.12--0.01)$ & 0.62 & 0.02 \\
T2DM & $13(2328)$ & $-0.01(-0.09-0.08)$ & 0.55 & 0.48 \\
Hyperlipidemia & $3(296)$ & $0.11(-0.19-0.41)$ & $<0.01$ \\
Healthy or control & $47(15,342)$ & $0.02(-0.01-0.06)$ & 0.21 \\
\hline
\end{tabular}

PON1 Paraoxonase 1 gene, SMD standardized mean difference, 95\% Cl 95\% confidence interval, HWE Hardy-Weinberg equilibrium, TG triglyceride, TC total cholesterol, $L D L-C$ low-density lipoprotein cholesterol, HDL-C high-density lipoprotein cholesterol, CHD coronary heart disease, T2DM type 2 diabetes mellitus

T2DM patients, hyperlipidemia patients and healthy subjects (Table 2).

\section{Heterogeneity analysis}

In the Ox-LDL association analysis, there was significant heterogeneity in the analysis with all comparisons $\left(I^{2}=\right.$ $79.8 \%, P_{\text {heterogeneity }}<0.01$ ). Two comparisons (Lakshmy R1 2010, Zhang $\mathrm{CH}$ 2016) were identified as the main contributors to the heterogeneity by using Galbraith plot. The SMD value and 95\% CI (SMD $=0.17,95 \%$ CI $\left.=0.03-0.31, \quad P_{\text {heterogeneity }}=0.27, P_{S M D}=0.02\right)$ did not change substantially after excluding these outlier comparisons.

In the lipids association analysis, there was significant heterogeneity in the total comparisons for TG $\left(I^{2}=58.2 \%\right.$, $\left.P_{\text {heterogeneity }}<0.01\right)$, TC $\left(I^{2}=44.5 \%, P_{\text {heterogeneity }}<0.01\right)$, LDL-C $\left(I^{2}=55.2 \%, P_{\text {heterogeneity }}<0.01\right)$ and HDL-C $\left(I^{2}=\right.$ $\left.69.8 \%, P_{\text {heterogeneity }}<0.01\right)$. Nine comparisons, 9 comparisons, 10 comparisons and 14 comparisons were respectively identified as the main contributors to the heterogeneity for TG, TC, LDL-C and HDL-C by using Galbraith plots. The SMD value and 95\% CI of TG (SMD $=0.03,95 \% \mathrm{CI}=0.00-0.06, P_{\text {heterogeneity }}=0.87, P_{S M D}=$ $0.03)$, LDL-C $\left(\mathrm{SMD}=0.02,95 \% \mathrm{CI}=0.00-0.05, P_{\text {heterogene- }}\right.$ ity $\left.=0.54, P_{S M D}=0.05\right)$ and HDL-C $(\mathrm{SMD}=0.01,95 \% \mathrm{CI}$ $\left.=-0.02-0.04, \quad P_{\text {heterogeneity }}=0.09, \quad P_{S M D}=0.42\right)$ did not change substantially after excluding these outlier comparisons. However, The SMD values and 95\% CIs of TC $\left(\mathrm{SMD}=0.01, \quad 95 \% \mathrm{CI}=-0.02-0.04, \quad P_{\text {heterogeneity }}=0.17\right.$, $\left.P_{S M D}=0.54\right)$ changed significantly after excluding these outlier comparisons.

\section{Publication bias test}

Begg's test and Egger's test were used to evaluate the publication bias of the included studies, and no publication bias was detected.

\section{Discussion}

Several meta-analyses [26-29] demonstrated that the $\mathrm{R}$ allele of rs662 polymorphism in PON1 is significantly associated with increased risk of CHD, but the underlying mechanisms have not yet been clarified. In the present study, we found that the $R$ allele of the rs662 polymorphism is significantly associated with increased levels of Ox-LDL, TG, TC and LDL-C, but there is no effect of the rs662 polymorphism on HDL-C was observed. It suggests that the association between the rs662 polymorphism and CHD may partly be mediated by high Ox-LDL levels as well as abnormal lipid levels caused by the variant $\mathrm{R}$ allele.

Dyslipidemia is closely associated with the progression of coronary atherosclerosis, and it accounts for around $50 \%$ of the population-attributable risk of CHD [30]. According to the 2013 ACC/AHA blood cholesterol guidelines [31] and the Adult Treatment Panel III (ATP III) Guidelines [32] of the United States, LDL-C was considered as the major cause of CHD and used as the primary target for therapy, and the other lipid parameters were used as the secondary or supplementary targets. Studies have shown that Ox-LDL was an independent risk factor for CHD [33, 34], and the underlying mechanisms possibly involved in promoting foam cells formation [35] and increasing endothelial injury [36], oxidative stress [37], and vascular inflammation [38].

Several possible reasons could be proposed to explain the association between the rs662 polymorphism and circulating Ox-LDL level. At first, PON1 play a major role in hydrolyzing Ox-LDL [39, 40], and the decreased levels of PON1 activity may lead to increase the circulating levels of Ox-LDL. Secondly, the decreased levels of PON1 activity might reduce the capacity of PON1-mediated inhibition of LDL-C oxidation $[41,42]$, which also leads to increase levels of circulating Ox-LDL [43]. In this meta-analysis, significantly higher levels of TG, TC and LDL-C were detected in the R carriers comparing with the subjects with the QQ genotype. The mechanisms in which the rs662 polymorphism modulates plasma lipid levels have not been clarified yet. One explanation could be that the rs662 polymorphism indirectly affects plasma lipid levels through the mediation of Ox-LDL. As mentioned above, increased Ox-LDL levels 


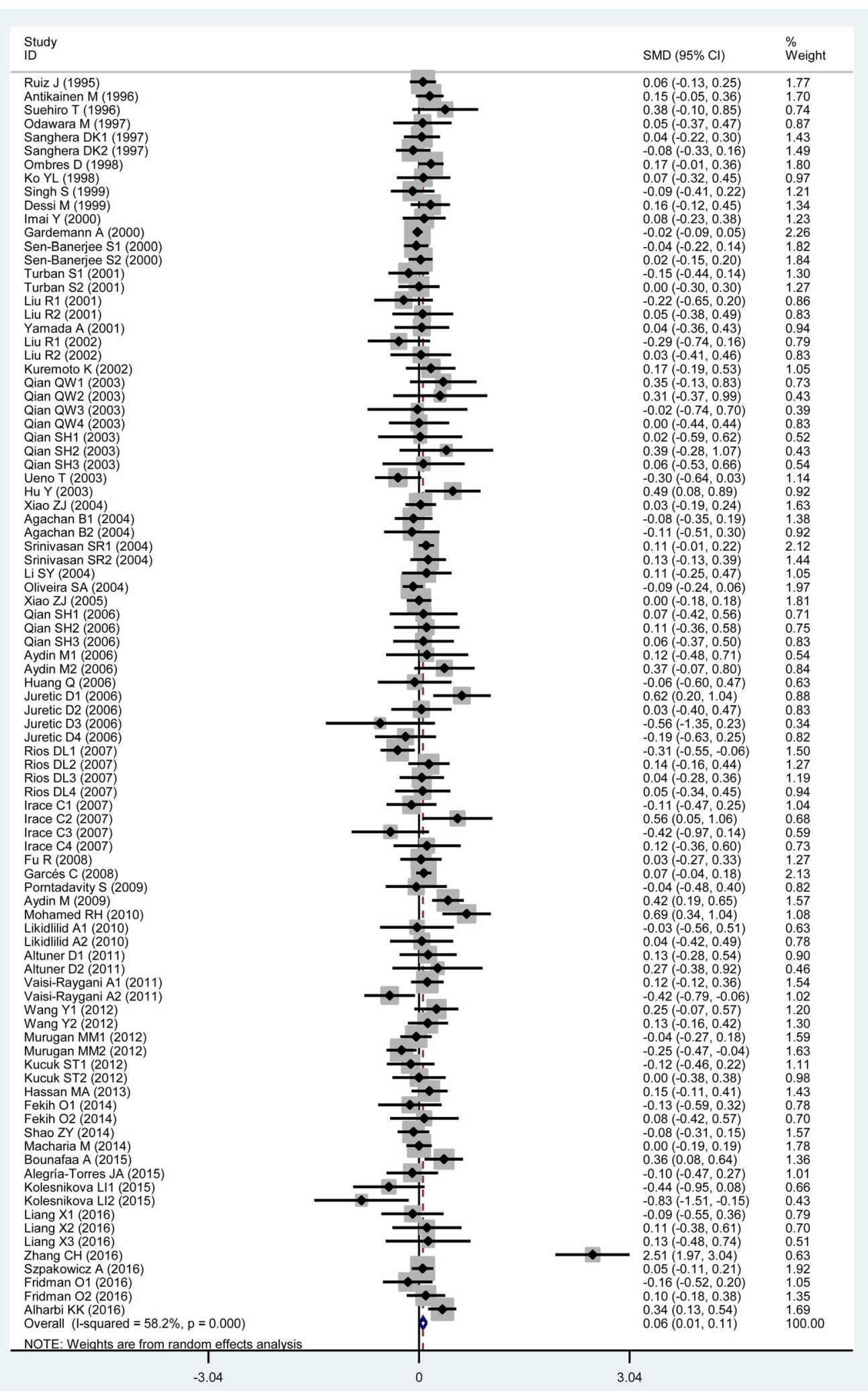

Fig. 3 Forest plot of the meta-analysis between the PON1 rs662 polymorphism and plasma triglycerides (TG) levels 


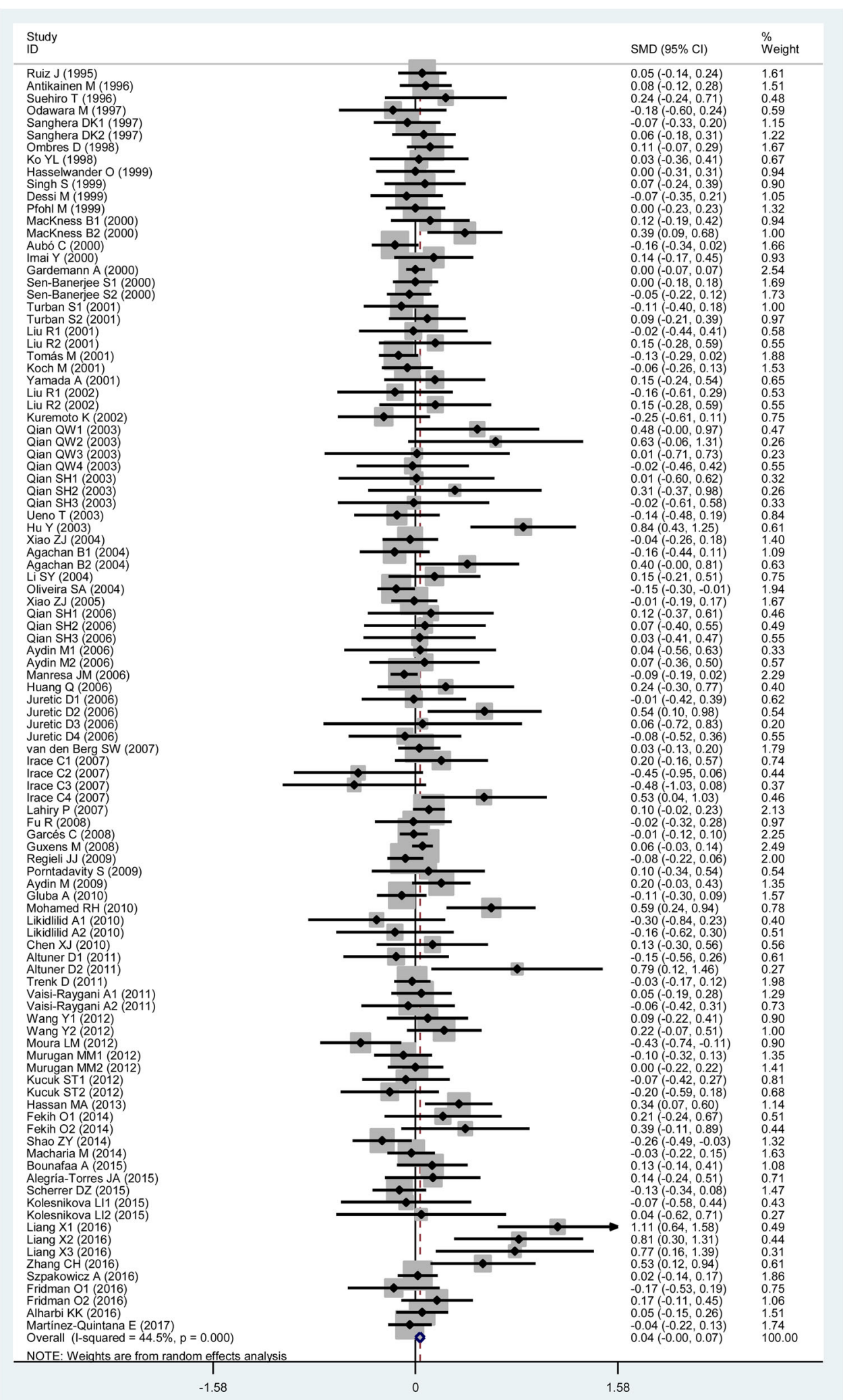

Fig. 4 Forest plot of the meta-analysis between the PON1 rs662 polymorphism and plasma total cholesterol (TC) levels 


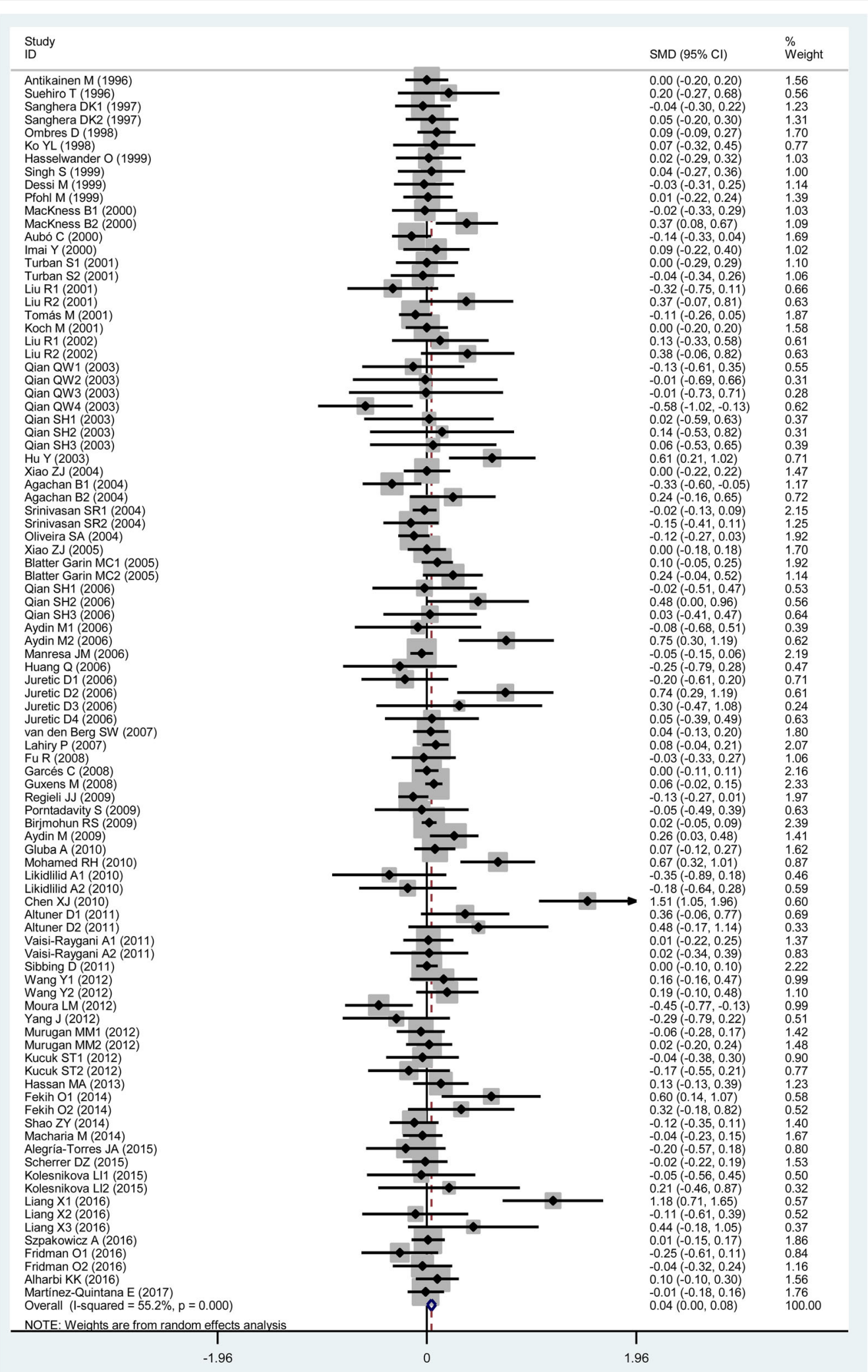

Fig. 5 Forest plot of the meta-analysis between the PON1 rs662 polymorphism and plasma low-density lipoprotein cholesterol (LDL-C) levels 


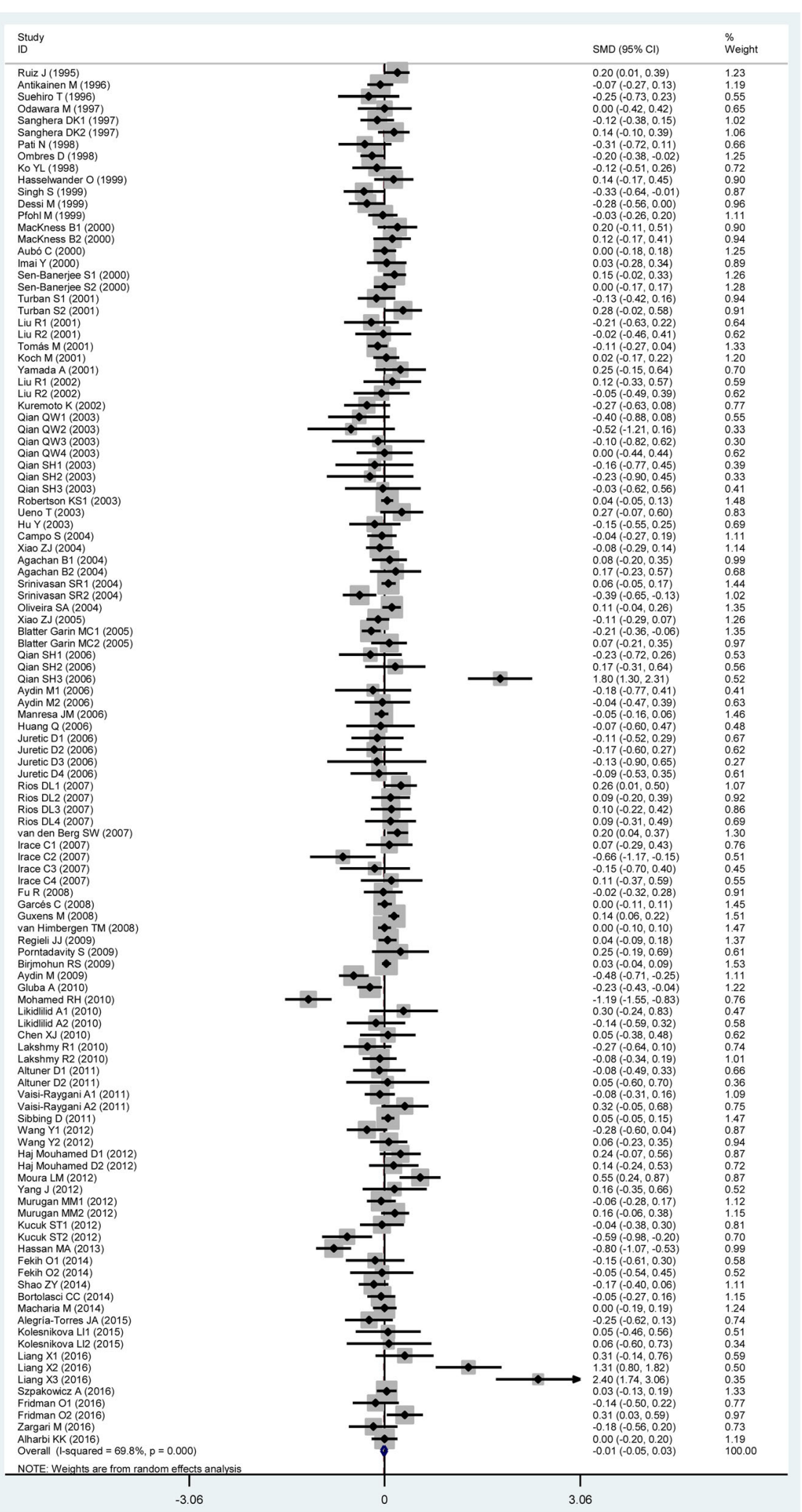

Fig. 6 Forest plot of the meta-analysis between the PON1 rs662 polymorphism and plasma high-density lipoprotein cholesterol (HDL-C) levels 
in blood can cause endothelial injury, oxidative stress, and vascular inflammation. All these events are likely to trigger the development of dyslipidemia [44-47].

In most of the studies included in Ox-LDL and lipids association analysis, a dominant model was used, i.e. $R R+Q R$ vs. QQ. Therefore, a dominant model was adopted in the meta-analysis between the rs662 polymorphism and plasma levels of Ox-LDL and lipids to ensure adequate statistical power. In subgroup analysis, we found that the differences in Ox-LDL, TG, TC and LDL-C levels between the genotypes were only from Asian populations, in which the SMD values were bigger when compared to those from Caucasians, Africans and the subjects of other ethnicities (Table 2). It indicates that there is an interaction between the rs662 polymorphism and ethnicity in modulating the plasma levels of Ox-LDL and lipids. The associations of the rs662 polymorphism with Ox-LDL, TG, TC and LDL-C in Asians were in line with the finding that there was a stronger association between the rs662 polymorphism and CHD in Asians than in other ethnicities $[26,27,48]$. Studies are needed to elucidate the reasons that the rs662 polymorphism had different effects on Ox-LDL, blood lipids and CHD risk in different ethnicities.

In the Ox-LDL and lipids association analysis, subgroup analysis by gender and health status were performed since they might be important factors affecting the associations between the rs662 polymorphism and plasma levels of Ox-LDL and lipids. For example, the present meta-analysis indicated that gender might modulate the association of the rs662 polymorphism with LDL-C levels since the significant association was only existed in females, but not in males (Table 2). Health status might also modulate the associations of the rs662 polymorphism with Ox-LDL and lipids levels. The significant association of the rs662 polymorphism with TC levels was only existed in healthy subjects, but not in the patients with CHD, T2DM and hyperlipidemia (Table 2). The significant associations of the rs662 polymorphism with Ox-LDL and HDL-C levels were only existed in CHD patients, but not in T2DM patients, hyperlipidemia patients and healthy subjects (Table 2).

Several limitations of the present meta-analysis should be noted. First of all, dyslipidemia is involved in a large number of genes as well as some environmental factors. However, the interactions of the rs662 polymorphism with other polymorphic loci or environmental factors on plasma levels of Ox-LDL and lipids have not been investigated in this meta-analysis due to the lack of original data from the included studies. In other words, more precise results could have been gained if more detailed individual data were available, or the stratification analyses based on the environmental factors such as diet, exercise, smoking status, etc., were performed. Secondly, a relatively small number of subjects were included in the association analysis for Ox-LDL due to the limited number of studies that met the inclusion criteria, which may reduce the statistic power and even cause type I error (false-positive results). Thirdly, this meta-analysis only included the studies published in English and Chinese as it is very difficult to get the full papers published in various languages.

\section{Conclusions}

The meta-analysis suggests that the rs662 polymorphism is significantly associated with abnormal levels of Ox-LDL and lipids, which may partly explain the significant association between the rs662 polymorphism and CHD.

\section{Additional files}

Additional file 1: The reference list for the studies included in the present meta-analysis. (DOCX 26 kb)

Additional file 2: Table S1. Characteristics of the individual studies included in the meta-analysis of Ox-LDL levels and plasma lipid levels for the PON1 rs662 polymorphism; Table S2. Ox-LDL levels by the genotypes of the PON1 rs662 polymorphism; Table S3. Plasma lipid levels by the genotypes of the PON1 rs662 polymorphism. (DOC $649 \mathrm{~kb}$ )

\section{Abbreviations}

95\% Cl: 95\% confidence interval; CHD: Coronary heart disease; HDL-C: Highdensity lipoprotein cholesterol; HWE: Hardy-Weinberg equilibrium; LDL-

C: Low-density lipoprotein cholesterol; Ox-LDL: Oxidized low-density lipoprotein; SMD: Standardized mean difference; T2DM: Type 2 diabetes mellitus; TC: Total cholesterol; TG: Triglycerides

\section{Acknowledgements}

This research was supported by the grants from the Key Project of Education Department of Sichuan Province, P. R. China (17ZA0172) and the Cooperative Project on Scientific Research between Nanchong city and North Sichuan Medical College, P. R. China (NSMC20170403).

\section{Funding}

This research was supported by the grants from the Key Project of Education Department of Sichuan Province, P. R. China (17ZA0172) and the Cooperative Project on Scientific Research between Nanchong city and North Sichuan Medical College, P. R. China (NSMC20170403).

\section{Availability of data and materials}

All data generated or analysed during this study are included in this published article [and its supplementary information files].

\section{Authors' contributions}

Zhi Luo and Lijun Pu conceived of the study, participated in the design, and drafted the manuscript. Zhi Luo, Lijun Pu, Irfan Muhammad, Yun Chen, Xiaogian Sun carried out the study searches and collected the data. Zhi Luo performed the statistical analyses. All authors read and approved the final manuscript.

Ethics approval and consent to participate Not applicable.

Consent for publication

Not applicable. 


\section{Competing interest}

The authors declare that they have no competing interests.

\section{Publisher's Note}

Springer Nature remains neutral with regard to jurisdictional claims in published maps and institutional affiliations.

\section{Received: 24 October 2018 Accepted: 29 November 2018} Published online: 13 December 2018

\section{References}

1. Mozaffarian D, Benjamin EJ, Go AS, Arnett DK, Blaha MJ, Cushman M, Das SR, de Ferranti S, Després JP, Fullerton HJ, Howard VJ, Huffman MD, Isasi CR, Jiménez MC, Judd SE, Kissela BM, Lichtman JH, Lisabeth LD, Liu S, Mackey RH, Magid DJ, McGuire DK, Mohler ER 3rd, Moy CS, Muntner P, Mussolino ME, Nasir K, Neumar RW, Nichol G, Palaniappan L, Pandey DK, Reeves MJ, Rodriguez CJ, Rosamond W, Sorlie PD, Stein J, Towfighi A, Turan TN, Virani SS, Woo D, Yeh RW, Turner MB. Heart Disease and Stroke Statistics-2016 Update: A report from the American Heart Association. Circulation 2016;133:e38-360.

2. Meisinger C, Baumert J, Khuseyinova N, Loewel H, Koenig W. Plasma oxidized low-density lipoprotein, a strong predictor for acute coronary heart disease events in apparently healthy, middle-aged men from the general population. Circulation. 2005:112:651-7.

3. O'Donnell FL, Stahlman S, Oetting AA. Incidence rates of diagnoses of cardiovascular diseases and associated risk factors, active component, U.S. armed forces, 2007-2016. MSMR. 2018;25:12-8.

4. Jakubowski H. Calcium-dependent human serum homocysteine thiolactone hydrolase. A protective mechanism against protein N-homocysteinylation J Biol Chem. 2000;275:3957-62.

5. Rosenblat M, Gaidukov L, Khersonsky O, Vaya J, Oren R, Tawfik DS, Aviram M. The catalytic histidine dyad of high density lipoprotein-associated serum paraoxonase-1 (PON1) is essential for PON1-mediated inhibition of low density lipoprotein oxidation and stimulation of macrophage cholesterol efflux. J Biol Chem. 2006:281:7657-65.

6. Aviram M, Rosenblat M, Bisgaier CL, Newton RS, Primo-Parmo SL, La Du BN. Paraoxonase inhibits high-density lipoprotein oxidation and preserves its functions. A possibleperoxidative role for paraoxonase. J Clin Invest. 1998; 101:1581-90.

7. Rosenblat M, Karry R, Aviram M. Paraoxonase 1 (PON1) is a more potent antioxidant and stimulant of macrophage cholesterol efflux, when present in HDL than in lipoprotein-deficient serum: relevance to diabetes. Atherosclerosis. 2006;187:74-81.

8. Mohamed RH, Mohamed RH, Karam RA, Abd El-Aziz TA. The relationship between paraoxonase1-192 polymorphism and activity with coronary artery disease. Clin Biochem. 2010:43:553-8.

9. Hassan MA, Al-Attas OS, Hussain T, Al-Daghri NM, Alokail MS, Mohammed AK, Vinodson B. The Q192R polymorphism of the paraoxonase 1 gene is a risk factor for coronary artery diseasein Saudi subjects. Mol Cell Biochem. 2013;380:121-8.

10. Shih DM, Gu L, Xia YR, Navab M, Li WF, Hama S, Castellani LW, Furlong CE, Costa LG, Fogelman AM, Lusis AJ. Mice lacking serum paraoxonase are susceptible to organophosphate toxicity andatherosclerosis. Nature. 1998; 394:284-7.

11. Qian QW, Qian SH, Wang SJ. Association of paraoxonase 1 arylersterase gene polymorphism in patients with type 2 diabetes and coronary heart disease. J Clin Cardiol (China). 2003:19:606-9.

12. Qian SH, Qian QW. Research of Arylesterase activity and its 192 polymorphism in patients with uremia patients with diabetic nephropathy. Chin J Nephrol. 2003;19:177-8.

13. Alharbi KK, Alharbi FK, Ghneim HK, Al-Sulaiman AM, Alodhayani AA, Tabassum SN, Khan IA. Amendment of amino acid in Q192R genetic polymorphism of paraoxonase 1 is a conventional risk factor for type 2 diabetes mellitus in the Saudi population. Int J Clin Exp Med. 2016;9:16605-12.

14. Bounafaa A, Berrougui $H$, Ghalim N, Nasser B, Bagri A, Moujahid A, Ikhlef S, Camponova P, Yamoul N, Simo OK, Essamadi A, Khalil A. Association between Paraoxonase 1 (PON1) polymorphisms and the risk of acute coronary syndrome in a north African population. PLoS One. 2015;10:e0133719.
15. Hu Y, Tian H, Liu R. Gln-Arg192 polymorphism of paraoxonase 1 is associated with carotid intima-media thickness inpatients of type 2 diabetes mellitus of Chinese. Diabetes Res Clin Pract. 2003;61:21-7.

16. Fekih O, Triki S, Hellara I, Neffati F, Rejeb J, Ommezzine A, Chouchane S, Guediche MN, Bouslama A, Najjar MF. Can paraoxonase 1 polymorphisms (L55 M and Q192 R) protect children with type 1 diabetes against lipid abnormalities? J Clin Lipidol. 2014;8:249-55.

17. Blatter Garin MC, Moren X, James RW. Paraoxonase-1 and serum concentrations of HDL-cholesterol and apoA-I. J Lipid Res. 2006;47:515-20.

18. Aydin M, Gokkusu C, Ozkok E, Tulubas F, Unlucerci Y, Pamukcu B, Ozbek Z, Umman B. Association of genetic variants in methylenetetrahydrofolate reductase and Paraoxonase-1 genes with homocysteine, folate and vitamin B12 in coronary artery disease. Mol Cell Biochem. 2009;325:199-208.

19. Irace C, Cortese C, Fiaschi E, Scavelli F, Liberatoscioli L, Federici G, Gnasso A. The influence of PON1 192 polymorphism on endothelial function in diabetic subjects with or without hypertension. Hypertens Res. 2008;31:507-13.

20. Huang Q, Liu YH, Yang QD, Xiao B, Ge L, Zhang N, Xia J, Zhang L, Liu ZJ. Human serum paraoxonase gene polymorphisms, Q192R and L55M, are not associated with the risk of cerebral infarction in Chinese Han population. Neurol Res. 2006:28:549-54.

21. Gardemann A, Philipp M, Hess K, Katz N, Tillmanns H, Haberbosch W. The paraoxonase Leu-Met54 and Gln-Arg191 gene polymorphisms are not associated with the risk of coronary heart disease. Atherosclerosis. 2000;152:421-31.

22. Ko YL, Ko YS, Wang SM, Hsu LA, Chang CJ, Chu PH, Cheng NJ, Chen WJ, Chiang CW, Lee YS. The GIn-Arg 191 polymorphism of the human paraoxonase gene is not associated with the risk of coronary artery disease among Chinese in Taiwan. Atherosclerosis. 1998;141:259-64.

23. Herrmann SM, Blanc H, Poirier O, Arveiler D, Luc G, Evans A, Marques-Vidal $P$, Bard JM, Cambien F. The GIn/Arg polymorphism of human paraoxonase (PON 192) is not related to myocardial infarction in the ECTIM Study. Atherosclerosis. 1996;126:299-303.

24. DerSimonian R, Kacker R. Random-effects model for meta-analysis of clinical trials: an update. Contemp Clin Trials. 2007;28:105-14.

25. Begg CB, Mazumdar M. Operating characteristics of a rank correlation test for publication bias. Biometrics. 1994;50:1088-101.

26. Deng Z, Xiang $H$, Gao W. Significant association between paraoxonase 1 rs662 polymorphism and coronary heart disease: a meta-analysis in the Chinese population. Herz. 2018. https://doi.org/10.1007/s00059-018-4737-8.

27. Zhang Z, Ou J, Cai P, Niu B, Li J. Association between the PON1 Q192R polymorphism and coronary heart disease in Chinese: a meta-analysis. Medicine (Baltimore). 2018;97:e11151.

28. Wang M, Lang X, Zou L, Huang S, Xu Z. Four genetic polymorphisms of paraoxonase gene and risk of coronary heart disease: a meta-analysis based on 88 case-control studies. Atherosclerosis. 2011;214:377-85.

29. Wheeler JG, Keavney BD, Watkins H, Collins R, Danesh J. Four paraoxonase gene polymorphisms in 11212 cases of coronary heart disease and 12786 controls: meta-analysis of 43 studies. Lancet. 2004;363:689-95.

30. Yusuf S, Hawken S, Ounpuu S, Dans T, Avezum A, Lanas F, McQueen M, Budaj A, Pais P, Varigos J, Lisheng L, Study Investigators INTERHEART. Effect of potentially modifiable risk factors associated with myocardial infarction in 52 countries (the INTERHEART study): case-control study. Lancet. 2004;364:937-52.

31. Stone NJ, Robinson JG, Lichtenstein AH, Bairey Merz CN, Blum CB, Eckel RH, Goldberg AC, Gordon D, Levy D, Lloyd-Jones DM, McBride P, Schwartz JS, Shero ST, Smith SC Jr, Watson K, Wilson PW, Eddleman KM, Jarrett NM, LaBresh K, Nevo L, Wnek J, Anderson JL, Halperin JL, Albert NM, Bozkurt B, Brindis RG, Curtis LH, DeMets D, Hochman JS, Kovacs RJ, Ohman EM, Pressler SJ, Sellke FW, Shen WK, Smith SC Jr, Tomaselli GF. American college ofCardiology/American Heart Association task force on practice guidelines. 2013 ACC/AHA guideline on the treatment of blood cholesterol to reduce atherosclerotic cardiovascular risk in adults: a report of the American College of Cardiology/American Heart Association task force on practice guidelines. Circulation. 2014;129:S1-45.

32. National Cholesterol Education Program. (NCEP) expert panel on detection, evaluation, and treatment of high blood cholesterol in adults (adult treatment panel III). Third report of the National Cholesterol Education Program (NCEP) expert panel on detection, evaluation, and treatment of high blood cholesterol in adults (adult treatment panel III) final report. Circulation. 2002;106:3143-421. 
33. Salonen JT, Ylä-Herttuala S, Yamamoto R, Butler S, Korpela H, Salonen R, Nyyssönen K, Palinski W, Witztum JL. Autoantibody against oxidised LDL and progression of carotid atherosclerosis. Lancet. 1992;339:883-7.

34. Toshima S, Hasegawa A, Kurabayashi M, Itabe H, Takano T, Sugano J, Shimamura K, Kimura J, Michishita I, Suzuki T, Nagai R. Circulating oxidized low density lipoprotein levels. A biochemical risk marker for coronary heart disease. Arterioscler Thromb Vasc Biol. 2000;20:2243-7.

35. Howell KW, Meng X, Fullerton DA, Jin C, Reece TB, Cleveland JC Jr. Toll-like receptor 4 mediates oxidized $L D L$-induced macrophage differentiation to foam cells. J Surg Res. 2011;171:e27-31.

36. Holvoet P. Endothelial dysfunction, oxidation of low-density lipoprotein, and cardiovascular disease. Ther Apher. 1999;3:287-93.

37. Weinbrenner $\mathrm{T}$, Cladellas M, Isabel Covas M, Fitó M, Tomás M, Sentí M Bruguera J, Marrugat J. High oxidative stress in patients with stable coronary heart disease. Atherosclerosis. 2003;168:99-106.

38. Yurdagul A Jr, Green J, Albert P, MC Ml, Mazar AP. Orr AW2. a5 $\beta 1$ integrin signaling mediates oxidized low-density lipoprotein-induced inflammation and earlyatherosclerosis. Arterioscler Thromb Vasc Biol. 2014;34:1362-73.

39. Shih DM, Xia YR, Wang XP, Miller E, Castellani LW, Subbanagounder G, Cheroutre H, Faull KF, Berliner JA, Witztum JL, Lusis AJ. Combined serum paraoxonase knockout/apolipoprotein E knockout mice exhibit increasedlipoprotein oxidation and atherosclerosis. J Biol Chem. 2000;275: $17527-35$

40. Fuhrman B, Partoush A, Aviram M. Acetylcholine esterase protects LDL against oxidation. Biochem Biophys Res Commun. 2004;322:974-8.

41. Ribeiro S, do Sameiro Faria M, Mascarenhas-Melo F, Freitas I, Mendonça ML, Nascimento H, Rocha-Pereira P, Miranda V, Mendonça D, Quintanilha A, Belo $\mathrm{L}$, Costa E, Reis F, Santos-Silva A. Main determinants of PON1 activity in hemodialysis patients. Am J Nephrol. 2012;36:317-23.

42. Nus M, Frances F, Sánchez-Montero JM, Corella D, Sánchez-Muniz FJ. WeW44:4 Arylesterase activity and HDL-cholesterol levels are dependent on the PON 55M and PON 192R polymorphisms. Atheroscler Suppl. 2006;7:333.

43. Jiang XL, Li M, Zhou JG, Yang QB, Du LJ, Du J. Plasma paraoxonase-1, oxidized low-density lipoprotein and lipid peroxidation levels in gout patients. Cell Biochem Biophys. 2011;61:461-6.

44. van Boven AJ, Jukema JW, Paoletti R. Endothelial dysfunction and dyslipidemia: possible effects of lipid lowering and lipid modifying therapy. Pharmacol Res. 1994;29:261-72.

45. Marques de Mattos A, Marino LV, Ovidio PP, Jordão AA, Almeida CC Chiarello PG. Protein oxidative stress and dyslipidemia in dialysis patients. Ther Apher Dial. 2012;16:68-74.

46. Yu Y, Lyons TJ. A lethal tetrad in diabetes: hyperglycemia, dyslipidemia, oxidative stress, and endothelial dysfunction. Am J Med Sci. 2005;330: 227-32

47. Aburawi EH, AlKaabi J, Zoubeidi T, Shehab A, Lessan N, Al Essa A, Yasin J, Saadi $H$, Souid AK. Subclinical inflammation and endothelial dysfunction in young patients with diabetes: a Study from United Arab Emirates. PLoS One. 2016;11:e0159808.

48. Lawlor DA, Day IN, Gaunt TR, Hinks LJ, Briggs PJ, Kiessling M, Timpson N, Smith GD, Ebrahim S. The association of the PON1 Q192R polymorphism with coronary heart disease: findings from the British Women's heart and health cohort study and a meta-analysis. BMC Genet. 2004;5:17.

\section{Ready to submit your research? Choose BMC and benefit from:}

- fast, convenient online submission

- thorough peer review by experienced researchers in your field

- rapid publication on acceptance

- support for research data, including large and complex data types

- gold Open Access which fosters wider collaboration and increased citations

- maximum visibility for your research: over $100 \mathrm{M}$ website views per year

At $\mathrm{BMC}$, research is always in progress.

Learn more biomedcentral.com/submissions 